Columbia Law School

Scholarship Archive

2013

\title{
Making Corporate Governance Codes More Effective: A Response to the European Commission's Action Plan of December 2012
}

\author{
Peter Böckli \\ Paul L. Davies \\ University of Oxford, Faculty of Law, paul.davies@law.ox.ac.uk \\ Eilis Ferran \\ University of Cambridge, Faculty of Law, evf1000@cam.ac.uk \\ Guido Ferrarini \\ University of Genoa, Law Department Centre for Law and Finance, guido.ferrarini@giuri.unige.it \\ José M. Garrido Garcia \\ University of Castilla-La Mancha, jgarridogarcia@yahoo.com
}

See next page for additional authors

Follow this and additional works at: https://scholarship.law.columbia.edu/faculty_scholarship

Part of the Business Organizations Law Commons, and the European Law Commons

\section{Recommended Citation}

Peter Böckli, Paul L. Davies, Eilis Ferran, Guido Ferrarini, José M. Garrido Garcia, Klaus J. Hopt, Alain Pietrancosta, Katharina Pistor, Markus Roth, Rolf Skog, Stanislaw Soltysinski, Jaap W. Winter \& Eddy Wymeersch, Making Corporate Governance Codes More Effective: A Response to the European Commission's Action Plan of December 2012, OxfORD Legal Studies ReSEARCH PAPER No. 56/2014 (2013). Available at: https://scholarship.law.columbia.edu/faculty_scholarship/2432

This Working Paper is brought to you for free and open access by the Faculty Publications at Scholarship Archive. It has been accepted for inclusion in Faculty Scholarship by an authorized administrator of Scholarship Archive. For more information, please contact scholarshiparchive@law.columbia.edu. 


\section{Authors}

Peter Böckli, Paul L. Davies, Eilis Ferran, Guido Ferrarini, José M. Garrido Garcia, Klaus J. Hopt, Alain Pietrancosta, Katharina Pistor, Markus Roth, Rolf Skog, Stanislaw Soltysinski, Jaap W. Winter, and Eddy Wymeersch 


\title{
Making Corporate Governance Codes More Effective A Response to the European Commission's Action Plan of December 2012
}

\author{
European Company Law Experts
}

Peter Böckli, Paul Davies, Eilis Ferran, Guido Ferrarini, José Garrido, Klaus J. Hopt, Alain Pietrancosta, Katharina Pistor, Markus Roth, Rolf Skog, Stanislaw Soltysinski, Jaap Winter, Eddy Wymeersch

\section{December 2013}

\section{The Action Plan of the European Commission of 12 December 2012}

In its Action Plan on European Company Law and Corporate Governance of 12 December 2012 the European Commission has announced its intention to improve the quality of corporate governance reports and in particular the quality of explanations which should be provided by listed companies that depart from the corporate governance code provisions, and envisaged to deal with this issue possibly by a non-legislative initiative still in 2013 . The European Commission had raised this issue in its Green Paper on The EU Corporate Governance Framework of 5 April 2011 since many companies have given no or only general or limited explanations for departing from code recommendations (cf. Study on Monitoring and Enforcement Practices in Corporate Governance in the Member States, September 2009 available at < http://ec.europa.eu/internal_market/company/ecgforum/studies_en.htm $>$; see also the international collection of codes on the website of the European Corporate Governance Institute, ECGI). In the answers to the European Commission' Green Paper a large majority of responses were favourable to requiring companies departing from the recommendations of corporate governance codes to provide detailed explanations for such departure, yet many respondents were against compulsory rules and most of the responses were against authorising monitoring bodies to check the informative quality of the explanations and possibly to require additional explanations (see Feedback Statement of 15 November 2011 questions 24 and 25). In quite a number of Member States various bodies in charge, associations and academics have dealt with this problem and introduced or proposed measures for improvement. Theoretically the upcoming discussion on behavioural economics and paternalism (nudge) is relevant (cf. C. R. Sunstein, The Yale L. J. 122 (2013) 1826). 


\section{Two meanings of effectiveness of the Code}

The concept of "codes' effectiveness" is ambiguous, depending on whether effectiveness refers to the level of adoption of the codes' recommendations themselves (substantive effectiveness) or only to the comply-explain mechanism (disclosure effectiveness). The first meaning of the expression leads to the question of the legitimacy and the quality of corporate governance codes. Indeed, we can assume that the legitimacy and the quality of the codes' content pave the way to effectiveness (through higher pressure on directors). We pass over the critique brought forward in some countries, in particular in Germany, that queries the pressure by private codes on constitutional grounds, since the clear majority of practice and academia disagrees.

Legitimacy is in the making: should there be any hard requirement regarding the recommendation making process? e.g. public consultations; composition of the entities in charge of the codes. In many countries, there seems to be a movement towards more diversity and public involvement in the process. In France for example, the fact that the main code lies exclusively in the hands of business associations has become subject to criticism, especially from the French Securities Commission, and, under the pressure of the Government that had plans to require a say on pay, the code was amended in June 2013. This "publicization" is of course a loss for the idea of self-regulation. This loss is also felt from the pressure exercised on the authors of the codes by the Government itself, by way of threatening to pass a law if acceptable professional guidelines could not be set. At least on some high-profile issues, the governments know to use the distrust of self-regulation and self-enforcement, resulting from a self-interested explanation of the crisis, in order to capture the authors of the codes and the concerned companies. This is blurring the line between non-binding codes and corporate law, as the former are more and more perceived as a government-controlled laboratory for the latter. If the legislators jump on the band-wagon of public criticism and pass a law without giving the private code-making bodies the occasion to deal with the issue, as it was the case several times in Germany and other countries (cf. K. J. Hopt, The American Journal of Comparative Law LIX (2011) 1, 16), this is legitimate and the line is clear. But it may still be problematic, because the idea of self-regulation will be weakened, in particular if private code rule reforms did not have the time to show that they would have been effective. 
Regarding the quality of the codes' content, some suggestions come to mind, for example, the necessary adaptations of the recommendations to the size, shareholder structure or legal forms of listed companies (the "one-size does not fit all" motto works here too; cf. the FTSE top 100/200/350); a cost-benefit analysis of the recommendations (ex ante and ex post) would also be useful. In many countries this is up to the standing corporate governance commission (as in Germany) or a similar body (as in France since 2013) that follows the reform needs and suggestions, reports on these in its annual report and decides or recommends how to react in the code. In France, the recent modification of the French Code (June 2013) instituted a "Haut Comité de suivi de l'application du Code", in charge with the application, interpretation and adaptation of the Code (see below). Two yearly global evaluations of the application of the Code are also performed by the Securities regulator and the authors of the Code.

The second meaning would put the focus on the quality of deviations' explanations. It is likely that a link exists between the two problems: the better norms, the fewer deviations. However, it should be stressed that deviations are still perfectly acceptable if well explained, good explanations not necessarily being long. Under these conditions, deviations seem to be well received by investors. Explanations are key to the success of the comply-or-explain mechanism and we know that there is still room for improvement here.

\section{Keeping the advantages of regulation by codes while finding adequate improvements of the quality of the reports and the explanations}

Making corporate governance codes more effective is certainly important and in principle will hardly be contested by anybody. The real problem is, as said before, what more effectiveness means and, correspondingly, what measures to take. There the consent may quickly dissolve and divergent answers and solutions will appear. It is therefore important for the European Commission not to jump right away to the question of what possible action to take, be it incentives, instruments or sanctions. It is true that the use of codes is a form of regulation, but it is a regulation that differs fundamentally from law, both compulsory and fall-back. The use of codes for regulating corporate governance in the forefront of the law is widely accepted in practice and in economic and legal theory because of its well-known advantages over legal rules. These advantages are among others flexibility, motivation to cooperate and to live up to best practice, adaptability to the challenges and needs of the national and international markets and possibility to try out new solutions and to change them easily if they do not prove successful (a sort of "legal experiments"). The "say on pay" as a corporate governance 
measure recommended by codes, just to give one example, has proven to be quite effective, even if not legally binding. These advantages motivated some countries such as Sweden that had started with a governmental corporate governance commission to give it away to business. Other countries have mixed models. The UK is moving away from the traditional mere self-regulation, the Financial Reporting Council being paid by the City, but its members being appoint by Government. In Belgium the chairman of the supervisory authority is member of the corporate governance commission. In other countries too there is an indirect or even direct influence of state authorities on the selection of the members of the code commission and sometimes on the content of the code itself.

The Achilles' heal of such codes are of course what impact they have and, if this is not satisfactory, the enforcement (Pietrancosta, RTDF 2011, 27, also in Festschrift für Hopt Berlin/New York 2010, vol. I, p. 1109; Wymeersch in Belcredi/Ferrarini, eds., Boards and Shareholders in European Listed Companies, Cambridge 2013, p. 67). Effectiveness of corporate governance codes by mere self-regulation as in the case of the former German Insider Trading Guidelines and the former German Takeover Code is fully depending on the good will of the addressees. This alone is not enough, because even if many of them comply, there are always some black sheep who do not cooperate and, even worse, profit from freeriding. This is inacceptable not only because it is unjust, but because it erodes the cooperativeness of the majority and in the end leads to the full breakdown of the code (lemon problem). Therefore it is now general international practice to require disclosure of compliance or not-compliance, whether by non-legal or legal means. This disclosure is needed in order to inform the fellow-addresses, the competitors, the financial press and the general public and on this basis to allow them to react by valuating the compliance or the noncompliance. This information must be meaningful, mere box-ticking and boiler plate language are not enough to activate the reaction mechanism at the market and in the public. But how is this to be to ensured?

\section{The relationship between the content of the corporate governance codes and disclosure}

Before one reflects on how disclosure can be improved and enforced, one has to take note of the special interrelationship between the content of the corporate governance code and the required disclosure. The European Commission is right in distinguishing in its Action Plan between improving the quality of corporate governance reports as such and the quality of 
explanations, and by doing so it is obviously conscious of the fact that the quality of the reports cannot be improved just by adding more recommendations to its content.

Some corporate governance codes, for example in Germany, Austria and Sweden, have three code layers. They do not only set and recommend best practice standards (i.e. the typical content of corporate governance codes), but contain two more levels of text: first a description of the legal rules on corporate governance which are usually contained in the country's stock corporation act and can be compulsory and fall-back, and second mere suggestions which can be deviated from without disclosure. It is important to distinguish such suggestions from code recommendations, the latter also not being binding, but subject to the disclosure requirement (comply or explain).

As to the first additional level, it is important to regulate fundamental questions of structure and competences of the company organs not in the code, but in the law where cogent rules can be set and civil and, if need be as in cases of fraud, criminal sanctions can be imposed. There are of course path dependent views on what should be regulated by law and what to be left to the code. In some countries such as Spain and Belgium the concept of independent directors is anchored in the law. If one overloads the code with such rules, it is obvious that mere disclosure, even if it is enforced, will and cannot be enough, but harsher enforcement is necessary. The danger involved is that this harsher enforcement will be applied to the whole code, i.e. also to genuine and legitimate code rules. This would not only be inappropriate, but would come at the expense of the above-mentioned advantages of the code and push regulation by codes near to regulation by law. As far as the description of corporate law in the code, this is meant to inform the public, in particular foreign investors, on the corporate governance system in the country, be it for avoiding misunderstandings, be it for attracting foreign investment. But this comes at the expense of the code becoming ponderous and occasionally even misleading because the description does not catch the details of the law as it is applied by the courts and the supervisory agencies.

The second additional level, i.e. mere suggestions, is particularly useful because it introduces a pre-stage to the actual code rules where one can do without disclosure and enforcement and still have the advantage of informing and advising about good behaviour, creating a general feeling for what could or should be done or omitted and finding out the reaction of the addressees and the market to the suggestions. 
It follows that, at the European level, general recommendations or even prescriptions to the Members States how to step up enforcement of corporate governance codes is dangerous because the corporate governance codes themselves differ in their just mentioned content. What could be useful instead is to suggest or recommend to the Member States to check the content of the codes as to the character of the rules contained therein and to make use of the method of the above-mentioned two or three text bodies. Only as to the body of recommendations in the corporate governance codes that really should be up to disclosure, one can meaningfully discuss on how to make the code and disclosure more effective.

\section{The optimal degree and the ways and means of disclosure, in particular the need of a "culture of departure from code recommendations"}

Disclosure is one of the key mechanisms for regulation and its enforcement in corporate and capital market law. There is abundant economic and legal theory on, as well as long-standing and broad international practice with (mandatory) disclosure that cannot be recapitulated here (cf. R. Kraakman et al., eds., The Anatomy of Corporate Law, 2d. ed., Oxford 2009, p. 277 et s.). But it should be stressed that more recently also the limits and costs of disclosure have come into the focus. Two main dangers must be avoided: Disclosure recommendations and/or requirements must avoid asking companies to make secret, confidential or otherwise internal information on the company unnecessarily available to the market and thereby to their competitors. Too much investor protection in this sense may harm competition. Asking for too much information is also a harmful burden on the companies that may be unnecessary for the investors and, even worse, may detract their attention from the really important information. In the last decades and in particular as a reaction to the financial crisis there has been a regulatory tendency in various fields to ever more increase the required disclosure with a cost and time burden that is no more justified by the aim of the regulation. It is submitted that "overinformation" is disinformation.

As far as disclosure in corporate governance reports is concerned, it goes without saying that half-truths may make the statement fully misleading and may even amount to deception and fraud to the public. This has been the case for some companies declaring directors to be independent who in reality were not. On the other hand it has already been mentioned before, that mere box-ticking and boiler plate language must be avoided and appropriate explanation is necessary. Several Member States have drawn attention to this and require explanations to be limited to the essential elements. The formerly used comply-or-disclose principle has not 
proved to be sufficient and has rightly been replaced in many jurisdictions by the comply-orexplain (i.e. comply or disclose and explain) principle. As required by the accounting directive in its June 2006 version, this disclosure, but not the code and its content, is supported by law, while outside the European Union the disclosure is sometimes asked for only by the (non-mandatory) code itself. Explanation is just needed if particular recommendations are departed from. The extent to which departure must be explained differs considerably. Some codes do not detail what "explain" means, others distinguish between the main principles and the lower-level principles of the code (cf. the UK Listing Rules), in some countries guidelines have been published on this (Belgium, the Netherlands). The abovementioned drawbacks of disclosure may be less relevant as to these explanations, but they still exist in view of the host and extreme details of many corporate governance recommendations, in particular in the context of groups of companies and as to the international dimension of the recommendations. The more complicated the facts are within and for the individual company, the more flexibility in following the code recommendations or departing from them in view of the specificities of the company is desirable. Therefore in some countries the phenomenon of many companies getting tired of the code movement is discernable and sometimes leads to the call for radically combing through the existing codes or, as by some extreme voices in Germany, even for abolishing them altogether and to regulating only by the democratically legitimate legislature.

In view of this trend the German and other Corporate Governance Commissions have explained that departing from the code is not in itself bad, but may be legitimate and even be good practice because of the specificities of the company, its sector and its environment. Therefore the expression used in the German Corporate Governance Code that departing from a recommendation of the code must be "justified" is misleading. It must be in the wellconsidered discretion of each company and each board to follow the code recommendations or, if it is in the interest of the company, to depart from them. The former chairman of the German Corporate Governance Commission has urged to develop what he called a "culture of departure from code recommendations", i.e. he has encouraged the companies not to shy back from not following the code (of course giving full explanations for why they do so). This developing culture must not be endangered by asking too much of explanation of departure.

It follows that appropriate explanation must not necessarily be long and wordy and that it need not to go into the details of the affairs and the corporate governance of the company. It rather should give a short, but convincing reason why following a particular recommendation 
of the code has not been considered to be in the interest of the company as seen by its board. Just stating that the board is of this opinion is of course not enough. After the code revision in France in June 2013 explanations should now be "comprehensible, relevant and detailed", "substantiated and adapted to the company's particular situation and must convincingly indicate why this specific aspect justifies an exemption", they "must state the alternative measures that have been taken if applicable, and must describe the actions that allow the company to comply with the aims of the relevant measure within the code". In the view of the ECLE the explanation should be concrete, for example stating the percentage of independent directors, the perceived need of directors with particular skills and experience in financial institutions, the special culture of a company and so on. For banks most of this is required under the recent CRD IV directive. Some countries such as Spain go further and do not just require an explanation of the deviation, but a general description on what is actually done in the company. If one sticks to the explanation model, it should not be recommended or even required that the board explains what alternatives to the recommended behaviour exist in the concrete situation, how the board has examined them and why it has chosen a specific way among other possibilities which diverts from the code obligation. This would make the explanation unnecessarily burdensome without adding value to the information. What counts is that the investors and the market know the fact that, and why the recommendation has not been followed in order to judge by themselves whether or not in their view this is good corporate governance for the specific company and to react accordingly.

\section{Improvements by incentives}

The quality of corporate governance reports and the explanations should primarily be improved by incentives rather than by imposing negative consequences in case of departures from the code. The basic idea of the corporate governance code movement is that the investors and the market will notice and react to, whether a company follows or not the best practice in the field, both national and international. It is therefore in the own interest of the company to follow the code or to explain why in a special case it does not follow it. It is of course well known that causal links between following corporate governance codes and the market price of the company have not yet been empirically proved. The relevant studies come up with different results or are only more or less conclusive. These studies need not to be documented here. But what is undisputable is the fact that management and boards fear the reaction of the peers, the investors and the markets and shy away from disclosing and 
explaining or give a favourable explanation that fits with the code but not with reality, a reaction that cannot be tolerated.

Possible ways and means to improve the incentives for following the code or explaining departures include therefore, first, making the corporate governance statements and the explanations better available: on the website of the company (this is already quite often done, since the boards want to display good practice, but this is only a mere pull measure) as well as to the financial press, the stock exchanges and the supervisory agencies (push measures). Second, good corporate governance reports and explanations could be evaluated, praised and even rewarded by the financial press, by shareholder associations, by stock exchanges, by auditors (already now if the corporate governance reports is part of the annual report) and possibly even by supervisory agencies. They could become part of the information investment advisors and funds would use for making their recommendations and investment decisions. All this can be done by non-legal means and by voluntary organization both of the companies concerned and the addressees of the reports and explanations.

\section{Improvements by sanctions, non-legal and legal}

Incentives may work better than sanctions, but sometimes they may not be enough, but need to be complemented be reactions ex post. Improvements of corporate governance codes and explanations may need in addition some sort of sanctions. In the following many possible sanctions and reactions are listed and briefly discussed. They are listed under the general heading of "improvements". This is not to say that each and every measure discussed in the following is considered to be an improvement in the technical sense of the word. As shown before, too much disclosure and too harsh and inappropriate sanctions may not only be unnecessary, but outright counterproductive.

Sanctions for non-disclosure or false disclosure can be non-legal, for example reprimand by stock exchanges, by shareholder associations, by professional organizations and by auditors. Stock exchanges could even, and some actually do, prescribe meaningful corporate governance reports and explanations as a condition for listing. Theoretically even whistleblowing as well as naming and shaming could be used, but these have not yet been proposed in the context of corporate governance codes and is not in conformity with the specific culture of a number of jurisdictions (it is well-known that here the traditions in the various countries differ considerably). 
In a number of countries the legislature has made compulsory not the corporate governance behaviour, i.e. following the code recommendations, but disclosing and explaining if certain code recommendations are departed from. The non-disclosure or false disclosure could lead to various legal sanctions beyond specific enforcement such as fines, legal liability for damages (Pietrancosta, RTDF 2011, 27, 35; in severe cases capital market fraud, but there are delicate problems with the causation, the calculation of damages and the standing to sue; as to the standing to sue there are various, highly controversial choices: corporate governance commission, minorities, individual shareholders or even the supervisory agency; also the question of discharge as in the UK arises) and administrative sanctions under capital market supervisory law (that more recently reach unheard of high fines) including naming and shaming and up to, in an extreme case of disobedience, holding a person inappropriate for acting as a director.

A relatively recent sanction is the possibility for investors to challenge the decision of the general assembly if it has not been informed correctly about the departure of the code by the board and the company. The latter sanction has been developed by German courts. It is an effective, but quite far-reaching means, and it is therefore not surprising that it has proven to be quite unpopular with the boards and the companies. Up to now only resolutions of discharge of the board can be nullified if the general assembly did not have full and clear information on the departures from the code. But several lower courts and legal academics have started to question also the validity of other kinds of resolution, for example election of board members who have violated the disclosure requirements. Occasionally even the validity of resolutions of the board is called into question. This should not be understood as a recommendation to the European Commission to go so far, but is just an example of possibilities of reaction including overreactions (cf. K. J. Hopt, The German Corporate Governance Kodex, in Festschrift für Hoffmann-Becking 2013, p. 563 at 574 et seq. with references). Theoretically also criminal sanctions may be available, but they do not seem to be the appropriate reaction in this field.

\section{Improvements by mobilizing private actors}

Sanctions alone are good, but not enough. They must be imposed and enforced. For this, first, formal approval by the board on the proposal of a corporate governance committee of the board, with presence of independent directors, might help. At least it would concentrate 
attention of board members on the issue. Second, the shareholders themselves could be empowered. For example a shareholder committee could be established in the company and entrusted with this task, though in case of controlled companies and groups this may not be very meaningful. Also other private actors could be mobilized such as institutional investors, proxy advisers and other gatekeepers, stock exchanges, shareholder associations, professional associations and others. This is in line with a broad international discussion on how to mobilize shareholders, investors and other private engagement in promoting good professional standards and helping to enforce code recommendations and legal requirements.

It is well known that the experiences made with this engagement are mixed, but in some countries such as France and the Netherlands they are good. As to corporate governance the corporate governance reports and the explanations could be made a specific point of the agenda of the general assembly, in the listing requirements of the stock exchanges with various degrees of requirements corresponding to different segments of listing (but this is relevant only for listed companies and delisting is no real alternative), in the checklists of the auditors (well known in auditing law as to annual reports) and others. Institutional investors could be engaged in this process by addressing such responsibilities in the Stewardship Codes and making clear that the concerted action concept does not hinder them to do so.

Provided that misleading disclosure may be a fraud on the market and give raise to liability, one possibility making corporate governance statements more serious, would consist in making sure that in any Member State, an action can be brought on the ground of false or misleading disclosed information, if this is not already sufficiently provided for by general civil or tort law.

\section{Improvements by charging public or private agents and agencies with inspection and monitoring}

In the above-mentioned answers to the Green Paper of the European Commission on corporate governance most of the responses were against involving monitoring bodies, in particular supervisory agencies, in the process of evaluating and improving corporate governance codes. But it should be noticed that in some countries such as Spain and Portugal the capital market commissions are indeed charged with such an evaluation in the context of their general supervision on the annual reports and that the commissions may impose sanctions in case of non-disclosure or wrong disclosure. It is true that giving state or quasi- 
state authorities this task may overburden them and will require definitely more means and personnel for them. Furthermore such competences to interfere with corporate governance codes are problematic because the character of the code changes. Depending on how far this involvement of state agencies reaches, the difference between code recommendations and regulation by actual law, be it compulsory or fall back, gets blurred and one risks to weaken the self-regulatory advantages of corporate governance codes, a danger that has been described at the beginning. This danger is avoided if the auditors of the company are charged to check whether the disclosure was meaningful or misleading, without being supposed to evaluate the business judgment of the boards. The result of the check could be included in the annual report or reported on separately.

An intermediate solution would be a stronger involvement of a privately structured corporate governance commission, where a panel composed of senior business people could invite companies with spurious corporate governance practices to discuss issues that have been identified from public statements of other sources. The panel would issue recommendations, no sanctions. In France, a new private body ("The High Committee in charge of monitoring the implementation of the code"), composed of four persons of recognized competence from international groups and three qualified persons representing investors and/or selected for their competence in legal and ethical matters, as provided for by the AFEP-MEDEF code of corporate governance (June 2013, Basdevant, RTDF 3/2013, 97 et seq., Paclot Bull. Joly Sociétés 2013, 558). This body will be able to receive questions from boards on any provision or interpretation of the code, for example as to the qualification of an independent director. It also will take action ex officio and seize the board of a company whenever it considers that such a company has failed to implement one of the code's recommendations without sufficient explanation. If a company decides not to follow the recommendations of the High Committee, it must mention in its annual report/reference document the latter's opinion and the reasons why it has decided not to act on its recommendations.

It goes by itself that private bodies must get the necessary personnel and financial means to do their job, if need be by a system of public-private co-financing, since self-regulation in corporate governance is in the public interest. But the necessary financing depends of course on what the body is charged to do. Full involvement of the capital market commissions as in Spain and Portugal is costly. 


\section{Summing up}

The intention of the European Commission to improve the quality of corporate governance reports and in particular the quality of explanations which should be provided by listed companies that depart from the corporate governance code provisions, is to be applauded, but the difficulties lie in the details of how to proceed. The initial challenge is to keep the advantages of regulation by codes while finding adequate improvements of the quality of the reports and the explanations. One must be aware that the content of the corporate governance codes and the kind and extent of disclosure are in a delicate relationship. There are various ways and means of improving disclosure and explanations, but one should also beware not to set counterproductive signals to a good "culture of departure from code recommendations". Improvements by incentives are preferable, but there are also various possibilities of improvements by sanctions, both non-legal and legal. As to enforcement it may be promising to mobilize the shareholders and investors and other private actors. In some countries public agents and agencies are charged with inspection and enforcement, but this is not without risks. Intermediate solutions would be to empower private bodies to discuss problems, to make suggestions and, if they are not followed, to ultimately recommend public disclosure. As to all this, in particular as to what body should be in charge of enforcement and what its composition should be, a one size fits all European rule is not advisable, even less so a maximum harmonization. There must be room for experimentation, regulatory competition and options that respect long standing national path dependencies. 